\title{
Mechanical influence of thread pitch on orthodontic mini-implant stability
}

\section{Amanda Carneiro da CUNHA Amanda Osório Ayres de FREITAS Mariana MARQUEZAN Lincoln Issamu NOJIMA}

Universidade Federal do Rio de Janeiro UFRJ, School of Dentistry, Department of Orthodontics, Rio de Janeiro, RJ, Brazil.

Declaration of Interests: The authors certify that they have no commercial or associative interest that represents a conflict of interest in connection with the manuscript.

\section{Corresponding Author:}

Lincoln Issamu Nojima

E-mail: linojima@gmail.com

DOI: 10.1590/1807-3107BOR-2015.vol29.0042

Submitted: Jul 31, 2014

Accepted for publication: Nov 24, 2014

Last revision: Jan 28, 2015
Abstract: The aim of this study was to evaluate the effect of pitch distance on the primary stability (PS) of orthodontic mini-implants (MIs) in artificial bone. Twenty experimental MIs were allocated to two groups, according to their geometric design: $G_{1}\left(30^{\circ} X 0.6 \mathrm{~mm}\right)$ and $G_{2}\left(45^{\circ} \times 0.8 \mathrm{~mm}\right)$, and inserted into artificial bone of different densities: $\mathrm{D}_{1}\left(0.32 \mathrm{~g} / \mathrm{cm}^{3}\right)$ and $\mathrm{D}_{2}\left(0.64 \mathrm{~g} / \mathrm{cm}^{3}\right)$. The maximum insertion torque (IT) and removal torque (RT) values were recorded in N.cm. Loss of torque (LT) values were obtained by calculating the difference between the IT and RT. MI mobility was measured by means of a Periotest assessment. Normality and homogeneity were determined by means of the Kolmogorov-Smirnov and Shapiro-Wilk tests, respectively. A two-way ANOVA was used to detect differences between the mini-implant design and density factors. The ANOVA/ Tukey tests were used to determine the intergroup difference. Higher IT values were observed for $G_{2}(p \leq 0.05)$ in $D_{2}$. No statistical difference for RT was observed between the groups, whereas $G_{2}$ presented higher values only for LT $(p \leq 0.05)$. The Periotest values (PTV) were higher for $G_{1}$, in comparison with $G_{2}$, in $D_{1}$. $G_{1}$ presented better PS in $D_{2}$ (IT, RT and LT), whereas $G_{2}$ was found to be more stable in $D_{1}$, after evaluation with Periotest.

Keywords: Mechanics; Orthodontic Anchorage Procedures; Materials Testing.

\section{Introduction}

The use of mini-implants represents an advance in contemporary orthodontics, in regard to controlling anchorage, thereby offering more satisfactory and predictable results. ${ }^{1}$ The ease of insertion and removal ${ }^{2}$ characterizes mini-implants (MI) as temporary anchorage devices (TADs), ${ }^{3}$ making them ideal for use in the case of undesirable osseointegration.

Among the main advantages of these devices is the possibility of inserting them in various areas of the maxilla and mandible, as well as in the alveolar bone and areas adjacent to tooth roots. ${ }^{4,5}$

However, failures may occur in using MI. ${ }^{6}$ These may be attributed to factors such as: site of insertion, ${ }^{3}$ bone overheating promoted by the bur during preparation of the orifice, absence of primary stability, gingival and peri-implant tissue inflammation, ${ }^{7}$ the surgical technique, the load application protocol and factors related to the patient, such as smoking and the practice of parafunctional habits. ${ }^{8}$ 
Artificial synthetic bone materials have been considered good alternatives for the purpose of performing mechanical tests, ${ }^{9,10}$ especially when evaluating the primary stability of MI, a factor frequently associated with greater MI success rates. ${ }^{11,12}$ MI biomechanical performance as regards primary stability may be evaluated by methods such as: insertion torque (IT), ${ }^{13}$ removal torque $(\mathrm{RT})^{14}$ and Periotest values (PTV). ${ }^{15,16}$

MI type and bone characteristic ${ }^{17}$ are other factors that may affect both the success rate and the MI permanence in the desired site. ${ }^{18}$ Variations in design, such as: diameter, length, thread width, pitch and tip format, may have an influence on stability and should be further evaluated. ${ }^{19,20,21,22}$ Thread depth and pitch have been associated with the possibility of enhancing the cutting efficiency of the mini-implant, by providing a lower insertion torque. In addition, an increase in the MI surface is related to MI support. ${ }^{20,23}$ Therefore, the aim of the present study was to evaluate the effect of pitch distance on the primary stability of orthodontic MIs in artificial bone of different densities.

\section{Methodology}

Twenty MIs made of Ti-6Al-4V alloy (Miniimplants for Orthodontic Anchorage, Sistema $\mathrm{INP}^{\mathrm{TM}}$, São Paulo, Brazil) $(1.6 \mathrm{~mm} \times 8 \mathrm{~mm})$ were used, and allocated to groups, according to their experimental geometric design: $\mathrm{G}_{1}\left(30^{\circ} \mathrm{X} 0.6 \mathrm{~mm}\right)$ (Figure 1) and $\mathrm{G}_{2}\left(45^{\circ} \mathrm{X} 0.8 \mathrm{~mm}\right)$ (Figure 2). The MIs were inserted into artificial bone developed for the purpose of biomechanical tests (Sawbones ${ }^{\mathrm{TM}}$ Pacific Research Laboratories Inc., Washington, USA), made from a block of solid polyurethane foam (180 X $130 \mathrm{~mm}$ and $40 \mathrm{~mm}$ thick) with different densities. Four test specimens were obtained $(130 \times 14 \times 18 \mathrm{~mm})$ and divided into two groups with the following densities: $D_{1}\left(0.32 \mathrm{~g} / \mathrm{cm}^{3}\right)$ and $\mathrm{D}_{2}\left(0.64 \mathrm{~g} / \mathrm{cm}^{3}\right)$. Five MIs were inserted into the artificial bone according to each screw design. For the purpose of sample calculation, we worked with data from a previous pilot study considering: $a=5 \%$ and power of study $=80 \%$. The division of the groups is shown in Table 1 .

MI insertion was performed with a torque wrench coupled to a digital torque meter. This made it possible

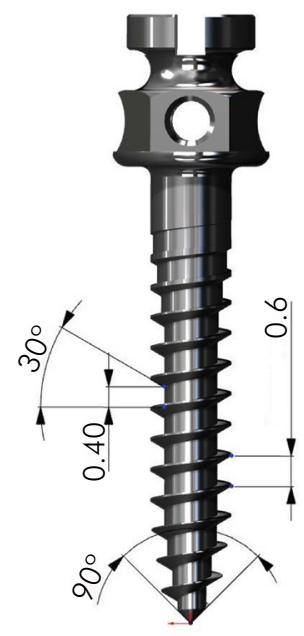

Figure 1: $G_{1}\left(30^{\circ} \times 0.6 \mathrm{~mm}\right)$.

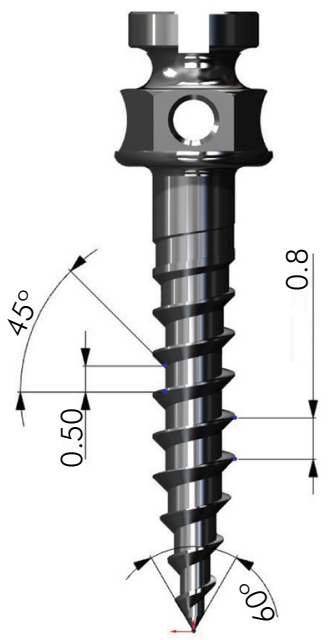

Figure 2: $G_{2}\left(45^{\circ} \times 0.8 \mathrm{~mm}\right)$.

Table 1. Division of the experimental groups.

\begin{tabular}{lcc}
\hline Groups & Geometric Design of Ml & Artificial Bone Density \\
\hline $\mathrm{G}_{1} \mathrm{D}_{1}$ & $30^{\circ} \times 0.6 \mathrm{~mm}$ & $0.32 \mathrm{~g} / \mathrm{cm}^{3}$ \\
$\mathrm{G}_{1} \mathrm{D}_{2}$ & $30^{\circ} \times 0.6 \mathrm{~mm}$ & $0.64 \mathrm{~g} / \mathrm{cm}^{3}$ \\
$\mathrm{G}_{2} \mathrm{D}_{1}$ & $45^{\circ} \times 0.8 \mathrm{~mm}$ & $0.32 \mathrm{~g} / \mathrm{cm}^{3}$ \\
$\mathrm{G}_{2} \mathrm{D}_{2}$ & $45^{\circ} \times 0.8 \mathrm{~mm}$ & $0.64 \mathrm{~g} / \mathrm{cm}^{3}$ \\
\hline
\end{tabular}


to insert the MIs and measure the maximum torque (IT) in N.cm, oriented perpendicular to the bone surface. ${ }^{24}$ The insertion site was previously perforated with a lance provided in the Kit from the manufacturer (Sistema INP ${ }^{\circledR}$, São Paulo, Brazil). A mechanical arm was used to support the torque meter, in order to standardize screw insertion. ${ }^{2}$

Mini-implant stability was measured by the Periotest (Medizintechnik Gulden $^{\text {TM }}$ e.K., Modautal, Germany). After the appliance was calibrated, two PTV measurements were made for each test specimen. The second measurement confirmed the validity of the first. If the second measurement presented values higher or lower than two units, in comparison with the first, the appliance was recalibrated and the measurements were taken again. The higher the PTV, the greater the MI mobility; therefore, the lower the MI stability.

The maximum RT values were recorded during miniimplant removal. It was possible to determine the loss of torque (LT) values by determining the difference between the maximum insertion and removal values. ${ }^{6}$
Statistical analysis was performed with the Statistical Package for the Social Science Program (version 17, SPSS Inc., Chicago, USA). The normality and homogeneity of the sample were confirmed by the Kolmogorov-Smirnov and Shapiro-Wilk tests, after which the ANOVA/Tukey tests were used to determine the intergroup difference. A two-way ANOVA test was then used to detect the differences between mini-implant design and density factors.

\section{Results}

The results of the comparisons between the groups for variables IT, RT, LT and PTV are expressed in Tables 2, 3,4 and 5, respectively.

No significant difference was observed between the groups, for IT in $\mathrm{D}_{1}$. However, higher IT values were observed in $\mathrm{D}_{2}$ for $\mathrm{G}_{2}(p \leq 0.05)$. The mini-implant design and density factors in the two-way ANOVA test account for $1.5 \%(p<0.0001)$ and $96.8 \%(p<0.0001)$ of the total variance, respectively.

Table 2. Insertion Torque Values.

\begin{tabular}{lccccc}
\hline Groups & Minimum & Maximum & Mean (N.cm) & Standard Deviation \\
\hline $\mathrm{G}_{1} \mathrm{D}_{1}$ & 4.2 & 5.7 & $5.02^{a}$ & 0.68 & Two-way ANOVA, \\
$\mathrm{G}_{2} \mathrm{D}_{1}$ & 4.6 & 6 & $5.40^{a}$ & 0.65 & density, $p<0.0001$ \\
$\mathrm{G}_{1} \mathrm{D}_{2}$ & 15.7 & 17.3 & $16.64^{b}$ & 0.73 & \\
$\mathrm{G}_{2} \mathrm{D}_{2}$ & 18.8 & 19.9 & $19.50^{\circ}$ & 0.43 & \\
\hline
\end{tabular}

Two-way ANOVA: condition, design; $p<0.0001$

One-way ANOVA: Different letters indicate statistical difference $-p \leq 0.05$ (ANOVA/Tukey).

Table 3. Removal Torque Values.

\begin{tabular}{lccccc}
\hline Groups & Minimum & Maximum & Mean (N.cm) & Standard Deviation \\
\hline $\mathrm{G}_{1} \mathrm{D}_{1}$ & 1.9 & 2.5 & $2.26^{a}$ & 0.23 & Two-way ANOVA, \\
$\mathrm{G}_{2} \mathrm{D}_{1}$ & 1.1 & 2.5 & $1.64^{a}$ & 0.54 & density, $p<0.0001$ \\
$\mathrm{G}_{1} \mathrm{D}_{2}$ & 7.8 & 9.8 & $8.76^{b}$ & 0.77 & \\
$\mathrm{G}_{2} \mathrm{D}_{2}$ & 6.5 & 11 & $8.46^{b}$ & 2.08 & \\
\hline
\end{tabular}

Two-way ANOVA: condition, design; $p=0.3855$

One-way ANOVA: Different letters indicate statistical difference $-p \leq 0.05$ (ANOVA/Tukey).

Table 4. Loss of Torque Values.

\begin{tabular}{lccccc}
\hline Groups & Minimum & Maximum & Mean $(\mathrm{N} . \mathrm{cm})$ & Standard Deviation & \\
\hline $\mathrm{G}_{1} \mathrm{D}_{1}$ & 2 & 3.3 & $2.76^{a}$ & 0.52 & Two-way ANOVA, \\
$\mathrm{G}_{2} \mathrm{D}_{1}$ & 3 & 4.9 & $3.76^{a}$ & 0.84 & density, $\mathrm{p}<0.0001$ \\
$\mathrm{G}_{1} \mathrm{D}_{2}$ & 5.9 & 9.4 & $7.88^{b}$ & 1.34 & \\
$\mathrm{G}_{2} \mathrm{D}_{2}$ & 8.4 & 13.2 & $11.04^{c}$ & 2.07 & \\
\hline
\end{tabular}

Two-way ANOVA: condition, design; $p=0.0030$

One-way ANOVA: Different letters indicate statistical difference $-p \leq 0.05$ (ANOVA/Tukey). 
Table 5. Periotest Values (PTV).

\begin{tabular}{lccccc}
\hline Groups & Minimum & Maximum & Mean & Standard Deviation & \\
\hline $\mathrm{G}_{1} \mathrm{D}_{1}$ & 21 & 27 & $23.40^{\circ}$ & 2.30 & Two-way ANOVA, \\
$\mathrm{G}_{2} \mathrm{D}_{1}$ & 15 & 19 & $16.80^{\mathrm{b}}$ & 1.64 & density, $\mathrm{p}<0.0001$ \\
$\mathrm{G}_{1} \mathrm{D}_{2}$ & 9 & 14 & $11.20^{c}$ & 2.16 & \\
$\mathrm{G}_{2} \mathrm{D}_{2}$ & 9 & 13 & $11.00^{c}$ & 1.58 & \\
\hline
\end{tabular}

Two-way ANOVA: condition, design; $p=0.0013$

One-way ANOVA: Different letters indicate statistical difference $-p \leq 0.05$ (ANOVA/Tukey).

No difference was observed between the groups ( $p \geq 0.05$ ), for the RT variable. The design factor accounts for $0.43 \%$ of the total variance in the two-way ANOVA test, but the effect of this factor is not considered significant $(p=0.3855)$. The density factor, however, accounts for $90.8 \%$ of the total variance, which was highly significant $(p<0.0001)$.

$\mathrm{G}_{2}$ presented a significant difference only in $\mathrm{D}_{2}(p \leq 0.05)$, for the LT variable. The design and density factors assessed by the two-way ANOVA test account for $8.7 \%(p=0.0030)$ and $77.4 \%(p<0.0001)$ of the total variance, respectively.

The PTV values were higher for the screw design of $\mathrm{G}_{1}$ in comparison with $\mathrm{G}_{2}$, when bone density was lower, indicating lower stability for $\mathrm{G}_{1}$, whereas there was no difference for $\mathrm{D}_{2}$ between the groups $(p \geq 0.05)$. Both design and density factors assessed by the two-way ANOVA test were considered very significant: $10 \%(p=0.0013)$ and $70.4 \%(p<0.0001)$ of the total variance, respectively.

\section{Discussion}

In the present study, a synthetic material was chosen to ensure that natural bone variables would not influence the results for the mini-implant geometric characteristics. ${ }^{25}$ Considering that previous studies have proven the impact of the cortical bone on mini-implant stability, ${ }^{26,27}$ it was decided that the tests would be performed with artificial bone, representing the medullary bone area. Studies such as these are important, especially in the case of patients with an absence of satisfactory cortical thickness and bone quality, as found by Martinelli et al. ${ }^{5}$ The densities chosen $\left(D_{1}=0.32 \mathrm{~g} / \mathrm{cm}^{3}\right.$ and $\left.D_{2}=0.64 \mathrm{~g} / \mathrm{cm}^{3}\right)$ correspond to the mean bone density in the posterior $\left(0.31 \mathrm{~g} / \mathrm{cm}^{3}\right)$ and anterior $\left(0.55 \mathrm{~g} / \mathrm{cm}^{3}\right)$ regions of the maxilla. ${ }^{28}$

Distinct thread angulations had to be established for each group, in order to maintain the same length of the devices and vary the distance of the pitch.
Therefore, $G_{1}$ threads presented an angulation of $30^{\circ}$ with a $0.6 \mathrm{~mm}$ pitch, whereas $\mathrm{G}_{2}$ threads presented an angulation of $45^{\circ}$ with a $0.8 \mathrm{~mm}$ pitch.

The IT was used in the study to evaluate primary stability, ${ }^{2,29,30}$ which is influenced by the morphological characteristics of the mini-implants. ${ }^{18}$ It was demonstrated that the $\mathrm{G}_{1}$ and $\mathrm{G}_{2}$ screws had similar IT values in the lower density bone sample. When the density was greater, the $\mathrm{G}_{2}$ screws had a higher IT $(19.50 \mathrm{~N} . \mathrm{cm})$ than that of $\mathrm{G}_{1}$ screws (16.64 N.cm) $(p \leq 0.05)$. These results, in reference to the IT variable in $\mathrm{D}_{2}$ bone $\left(0.64 \mathrm{~g} / \mathrm{cm}^{3}\right)$, may be explained by the design of the screws used, which differed in angulation and pitch distance. $\mathrm{G}_{2}$ had more close-fitting contact with the adjacent tissues, therefore, demanding higher insertion torque, compared with $\mathrm{G}_{1}$.

When evaluating the IT results independently of the screw design, higher IT was obtained when the bone density was greater, corroborating the finding that insertion of screws into bone of greater density generates higher stability values. ${ }^{30}$

An appropriate insertion torque allows ideal initial anchorage to be achieved; conversely, excessive torque increases the failure rate. ${ }^{13}$ The levels of insertion torque obtained in the present study $(5.02-19.50 \mathrm{~N} . \mathrm{cm})$ exceeded the ideal range of torque recommended for obtaining stability in human bone (5-10 N.cm). This variance may be attributed to the physical characteristics inherent to artificial bone. ${ }^{29}$

As regards RT, no difference was observed between the two screw designs, in bone of the same density. $G_{1}$ and $G_{2}$ behaved in a similar manner in $D_{1}$, and showed lower RT values than in $\mathrm{D}_{2}$. In addition, it may be observed that the RT values obtained in the present study were lower than the IT values, a result that had been expected seeing that this was an in vitro trial, and that there was no influence exerted by either secondary stability or osseointegration factors. 
The LT variable showed a difference between the two screw designs, only when the denser bone was used. $G_{1}$ showed lower loss of torque in comparison with $\mathrm{G}_{2}$. When the IT and RT variables were analyzed separately, one could note that the higher IT in $\mathrm{G}_{2}$ did not afford greater primary stability, since the RT values proved the same for both groups. Therefore, $G_{1}$ presented better general performance in denser bone, in comparison with the other group. The IT and RT variables appear more sensitive in detecting differences in primary stability between screws, when using bone of greater density.

The Periotest appliance proved more sensitive in detecting differences in screw stability when $\mathrm{D}_{1}$ was used, in which higher values were observed for $\mathrm{G}_{1}(p \leq 0.05)$, therefore, lower screw stability. The result indicates that $\mathrm{G}_{2}$ showed better primary stability in bone of less density considering the disposition of the pitch at $45^{\circ}$ and the longer distance of the pitches, favoring less bone cutting.

The Periotest was developed with the objective of measuring the level of periodontal integration of the tooth and the rigidity at the bone/implant interface. ${ }^{31}$ Some studies have assessed its efficacy in measuring the primary stability of implants, and have observed that this method was capable of evaluating variations in bone composition..$^{15,16}$

When evaluating the types of trials that were conducted, one observes that the IT and RT are tests in which the force is applied in the axial direction, whereas the Periotest evaluates stability in the laterolateral direction; therefore, these tests can be considered complementary. Moreover, it was observed that the tests performed in the axial direction were sensitive only for greater density, whereas the laterolateral test was capable of presenting statistical results at lower density.

Laterolateral tests are of notable importance, considering that the forces exerted on these devices, when used in a clinical setting, commonly occur in this direction.

\section{References}

1. Baumgaertel S, Razavi MR, Hans MG. Mini-implant anchorage for the orthodontic practitioner. Am J Orthod Dentofacial Orthop. 2008 Apr;133(4):621-7.

2. Pithon MM, Nojima MG, Nojima LI. In vitro evaluation of insertion and removal torques of orthodontic mini-implants. Int J Oral Maxillofac Surg. 2011 Jan;40(1):80-5.
The results indicated that the angle of the design and the distance of the pitch were significant enough to influence the primary stability, even when only the corresponding portion of the medullary bone is present. Nevertheless, the design of this study must be reproduced in an ex vivo or in vivo model to validate the results found with artificial bone. Moreover, other studies that take other variables into consideration should be performed, such as the cortical and bone maturation that occurs at the bone/implant interface during the healing period. ${ }^{26}$

\section{Conclusion}

The variation in mini-implant pitch distance was significant enough to influence all of the variables that measured primary stability (IT, RT and PTV).

In analyzing the IT and RT stability measurements (gauged in the axial direction), the MI pitch distance variation influenced stability only in greater density bone. In contrast, in analyzing the PTV measurement (that uses laterolateral forces), the difference in stability was observed between the groups only in lower density bone.

The mini-implants with a shorter pitch distance and an insertion angle of $30^{\circ}\left(G_{1}\right)$ presented better primary stability in artificial bone of greater density.

The mini-implants with a longer pitch distance and an insertion angle of $45^{\circ}\left(G_{2}\right)$ were found to be more stable in artificial bone of lower density, after evaluation with the Periotest.

\section{Acknowledgements}

The authors acknowledge the financial support given by Coordenação de Aperfeiçoamento de Pessoal de Nivel Superior - CAPES (Brazilian government) and FAPERJ - Fundação Carlos Chagas Filho de Amparo à Pesquisa do Estado do Rio de Janeiro.

3. Park HS, Jeong SH, Kwon OW. Factors affecting the clinical success of screw implants used as orthodontic anchorage. Am J Orthod Dentofacial Orthop. 2006 Jul;130(1):18-25.

4. Schnelle MA, Beck FM, Jaynes RM, Huja SS. A radiographic evaluation of the availability of bone for placement of miniscrews. Angle Orthod. 2004 Dec;74(6):832-7. 
5. Martinelli FL, Luiz RR, Faria M, Nojima LI. Anatomic variability in alveolar sites for skeletal anchorage. Am J Orthod Dentofacial Orthop. 2010 Sep;138(3):252.e1-9.

6. Alves Jr M, Baratieri C, Nojima LI. Assessment of miniimplant displacement using cone beam computed tomography. Clin Oral Implants Res. 2011 Oct;22(10):1151-6.

7. Chen Y, Shin HI, Kyung HM. Biomechanical and histological comparison of self-drilling and self-tapping orthodontic microimplants in dogs. Am J Orthod Dentofacial Orthop. 2008 Jan;133(1):44-50.

8. Chen Y, Kyung HM, Zhao WT, Yu WJ. Critical factors for the success of orthodontic mini-implants: a systematic review. Am J Orthod Dentofacial Orthop. 2009 Mar;135(3):284-91.

9. Chen Y, Kyung HM, Gao L, Yu WJ, Bae EJ, Kim SM. Mechanical properties of self-drilling orthodontic micro-implants with different diameters. Angle Orthod. 2010 Sep;80(5):821-7.

10. Gracco A, Giagnorio C, Incerti Parenti S, Alessandri Bonetti G, Siciliani G. Effects of thread shape on the pullout strength of miniscrews. Am J Orthod Dentofacial Orthop. 2012 Aug;142(2):186-90.

11. Motoyoshi M, Matsuoka M, Shimizu N. Application of orthodontic mini-implants in adolescents. Int J Oral Maxillofac Surg. 2007 Aug;36(8):695-9.

12. Inaba M. Evaluation of primary stability of inclined orthodontic mini-implants. J Oral Sci. 2009 Sep;51(3):347-53.

13. Motoyoshi M, Hirabayashi M, Uemura M, Shimizu $\mathrm{N}$. Recommended placement torque when tightening an orthodontic mini-implant. Clin Oral Implants Res. 2006 Feb;17(1):109-14.

14. Favero LG, Pisoni A, Paganelli C. Removal torque of osseointegrated mini-implants: an in vivo evaluation. Eur J Orthod. 2007 Oct;29(5):443-8.

15. Meredith N, Friberg B, Sennerby L, Aparicio C. Relationship between contact time measurements and PTV values when using the Periotest to measure implant stability. Int J Prosthodont. 1998 May-Jun;11(3):269-75.

16. Lachmann S, Jäger B, Axmann D, Gomez-Roman G, Groten $\mathrm{M}$, Weber $\mathrm{H}$. Resonance frequency analysis and damping capacity assessment. Part I: an in vitro study on measurement reliability and a method of comparison in the determination of primary dental implant stability. Clin Oral Implants Res. 2006 Feb;17(1):75-9.

17. Marquezan M, Lima I, Lopes RT, Sant'Anna EF, de Souza MM. Is trabecular bone related to primary stability of miniscrews? Angle Orthod. 2014 May;84(3):500-7.

18. Boyle JM, Frost DE, Foley WL, Grady JJ. Torque and pullout analysis of six currently available self-tapping and "emergency" screws. J Oral Maxillofac Surg. 1993 Jan;51(1):45-50.
19. Squeff LR, Simonson MB, Elias CN, Nojima LI. Caracterização de mini-implantes utilizados na ancoragem ortodôntica. Rev Dent Ortodon Ortop Facial. 2008 Sep-Oct;13(5):49-56. DOI: 10.1590/S1415-54192008000500006.

20. Brinley CL, Behrents R, Kim KB, Condoor S, Kyung HM, Buschang $\mathrm{PH}$. Pitch and longitudinal fluting effects on the primary stability of miniscrew implants. Angle Orthod. 2009 Nov;79(6):1156-61.

21. Crismani AG, Bertl MH, Celar AG, Bantleon HP, Burstone CJ. Miniscrews in orthodontic treatment: review and analysis of published clinical trials. Am J Orthod Dentofacial Orthop. 2010 Jan;137(1):108-13.

22. Motoyoshi M, Yano S, Tsuruoka T, Shimizu N. Biomechanical effect of abutment on stability of orthodontic miniimplant. A finite element analysis. Clin Oral Implants Res. 2005 Aug;16(4):480-5.

23. Motoyoshi M, Inaba M, Ueno S, Shimizu N. Mechanical anisotropy of orthodontic mini-implants. Int J Oral Maxillofac Surg. 2009 Sep;38(9):972-7.

24. Pithon MM, Nojima LI. Avaliação da estabilidade primária de mini-implantes ortodônticos em diferentes regiões da maxila e mandíbula de porcos. Innov Implant J. 2007 Dec;2(4):58-63.

25. Migliorati M, Signori A, Silvestrini-Biavati A. Temporary anchorage device stability: an evaluation of thread shape factor. Eur J Orthod. 2012 Oct;34(5):582-6.

26. Huja SS, Rao J, Struckhoff JA, Beck FM, Litsky AS. Biomechanical and histomorphometric analyses of monocortical screws at placement and 6 weeks postinsertion. J Oral Implantol. 2006;32(3):110-6.

27. Brettin BT, Grosland NM, Qian F, Southard KA, Stuntz TD, Morgan TA, et al. Bicortical vs monocortical orthodontic skeletal anchorage. Am J Orthod Dentofacial Orthop. 2008 Nov;134(5):625-35.

28. Devlin H, Horner K, Ledgerton D. A comparison of maxillary and mandibular bone mineral densities. J Prosthet Dent. 1998 Mar;79(3):323-7.

29. Lim SA, Cha JY, Hwang CJ. Insertion torque of orthodontic miniscrews according to changes in shape, diameter and length. Angle Orthod. 2008 Mar;78(2):234-40.

30. Marquezan M, Osório A, Sant'Anna E, Souza MM, Maia L. Does bone mineral density influence the primary stability of dental implants? A systematic review. Clin Oral Implants Res. 2012 Jul;23(7):767-74.

31. Canakci V, Orbak R, Tezel A, Canakci CF. Clinical response to experimental forces and non-surgical therapy of teeth with various alveolar bone loss. Dent Traumatol. 2002 Oct;18(5):267-74. 